\title{
Role of VAC Dressing in the Large Open Fracture: A Single Center Prospective Study from Indore
}

\author{
Himanshu Suman ${ }^{1}$, Jyoti Krishna, Yash Sharma ${ }^{3}$, Prakhar Jain ${ }^{4}$, \\ Surendra Parmar 5
}

${ }^{1}$ Senior Resident, Department of Orthopaedics, Index Medical College, Hospital and Research Center

${ }^{2,3,4,5}$ PG Resident, Department of Orthopaedics, Index Medical College, Hospital and Research Center

Corresponding Author: Surendra Parmar

\begin{abstract}
Background: As the body's protective skin barrier is breached in open fractures, and the potential of contamination is high, these can lead to significant morbidity. Vacuum-assisted closure (VAC) is the application of the negative pressure in open wounds, and it significantly improves wound healing both at the macro and micro levels.

Material and Method: A total of 30 patients (23 males and 7 females with a mean age of 27 years) with large open fractures of long bones who received VAC therapy during the early period of treatment were studied. VAC dressing over wound was done following percutaneous pinning or external fixation. In addition, rates of infection, fracture union, duration of application of VAC, and the association of duration of VAC with the development of complications were evaluated.
\end{abstract}

Results: The mean time between the trauma and the first debridement was 8.20 hours (range, 223 ). The mean duration of VAC application was ten days (range, 3-16). Delayed wound closure was performed in nine patients. In the remaining 21 patients, the mean decrease in the wound dimensions between pre and post-VAC application was found to be $43.06 \%$ (range, 20$60 \%$ ).

Conclusion: VAC application increases the patient's comfort by reducing the need for dressing changes, improves blood circulation, accelerates the formation of granulation tissue, reduces the rate of infection from the hospital environment, decreases edema, alleviates the need for secondary interventions, and also decreases wound dimensions.
Keywords: wound, open fractures, vacuumassisted closure, wound healing

\section{INTRODUCTION}

Open fractures account for one of the most common problems encountered in orthopedic practice. They are frequently associated with osteomyelitis and an increased rate of deep infections. The infection rate demonstrated in many studies was found to be $16-66 \%$ in open fractures. ${ }^{1-8}$

As the body's protective skin barrier is breached in open fractures, and the potential of contamination is high, these can lead to significant morbidity. The treating surgeon must consider the following: the patient's condition, the mechanism of injury, and the fracture type. Each fracture should be treated differently depending upon the above-mentioned factors.

Vacuum-assisted closure (VAC) is the application of the negative pressure in open wounds, and it significantly improves wound healing both at the macro and micro levels. ${ }^{10}$ Advantages of VAC include, it completely isolates the wound that decreases the risk of secondary contamination from the environment and secondly, it reduces edema from the limb. Removal of edema improves capillary blood flow, which in turn increases the delivery of oxygen and nutrients to the wound. 11-13 VAC also limits the proliferation of bacteria because of capillary in growth into the wound. This provides the oxygen and 

Indore.

immune cells that antagonize bacterial growth. ${ }^{14}$

Evidence of the usefulness of VAC in the Indian population is limited. Hence, in the present study, we tried to elucidate the effect of VAC dressing in a large open fracture.

\section{MATERIAL AND METHOD}

A total of 30 patients ( 23 males and 7 females with a mean age of 27 years) with large open fractures of long bones who received VAC therapy during the early period of treatment were studied. Patients with diabetes mellitus, rheumatoid arthritis, and immune-compromised conditions were excluded from the study.

The mean duration of the follow-up and hospitalization were $26.57 \pm 15.25$ months (range, 9-52 months) and $31.51 \pm 21.46$ days (range, 8-75 days), respectively. Patients were evaluated in terms of soft tissue and bone defects, periosteal stripping, major vascular injury, compartment syndrome, and contamination at the emergency service. For the patients who were considered to have a vascular injury, a computed tomography (CT) angiography was performed. Twenty-three patients had lower extremity, and seven patients had upper extremity injuries. Fractures were classified as per the GustiloAnderson classification. Bone and soft tissues that had lost vitality were debrided and irrigated. VAC dressing over wound was done following percutaneous pinning or external fixation. All patients underwent a thorough intraoperative debridement with stabilization of the fractures, commonly with an external fixator.

For antibiotic prophylaxis, Ceftriaxone $1 \mathrm{~g}$ was administered every eight hours, and gentamicin $80 \mathrm{mg}$ was applied for 7 days every 12 hours. In cases that developed an infection, antibiotic treatment was adjusted according to the culture and sensitivity results. Following the last VAC application, wound dimensions were evaluated using the wound dimensions In addition, rates of infection, fracture union, duration of application of VAC, and the association of duration of VAC with the development of complications were evaluated.

Statistical analysis using SPSS for Windows 20.0 (SPSS Inc, Chicago, IL, USA) program was performed. Student's $t$ test and Mann-Whitney U test were used in the evaluation of parametric and nonparametric variables, respectively. Categorical data were compared using a chisquare test. $\mathrm{P}<0.05$ was accepted as statistically significant.

\section{RESULTS}

The mean time between the trauma and the first debridement was 8.20 hours (range, 2-23). Osteosynthesis was obtained with an external fixator $(n=19)$, percutaneous pinning $(n=5), \quad E F+$ percutaneous pinning $(\mathrm{n}=5), \quad$ and conservative treatment $(n=6)$. Meantime to union was 5.03 \pm 1.58 months (range, 3-8 months). The mean duration of VAC application was ten days (range, 3-16). Delayed wound closure was performed in nine patients. In the remaining 21 patients, the mean decrease in the wound dimensions between pre and post-VAC application was found to be $43.06 \%$ (range, 20-60\%).

A deep infection developed in eight $(38.1 \%)$ out of twenty-one patients who underwent secondary closure, of whom three patients (14.3\%) developed osteomyelitis. Statistically, a significant difference was found between the primary and secondary closure in terms of deep infection $(\mathrm{p}=0.028)$. Out of seven patients, none of the patients who underwent delayed primary closure developed an infection. The microbes that caused infection were pseudomonas aeruginosa, staphylococcus haemolyticus, acinetobacter baumannii, and klebsiella pneumoniae. The infection was treated through antibiotherapy and debridement in those patients. However, one patient developed osteomyelitis and treated surgically. No statistically significant association found between dimensions of the first wound and development of 

Indore.

infection $(\mathrm{p}=\mathrm{NS})$. No association was found between the trauma type and the development of infection $(\mathrm{p}=\mathrm{NS})$. Union was achieved in the 20th month in two patients.

Table 1: Comparison of Closure Techniques

\begin{tabular}{|l|l|l|l|}
\hline Parameters & Delayed primary closure $(\mathbf{n}=\mathbf{9})$ & Secondary closure $(\mathbf{n}=\mathbf{2 1})$ & $\mathbf{P}$ \\
\hline Age $($ year \pm sd) & $33.73 \pm 5.90$ & $25.92 \pm 4.21$ & 0.224 \\
\hline Time between trauma-initial debridement (hour \pm sd) & $3.84 \pm 0.64$ & $9.72 \pm 2.15$ & 0.002 \\
\hline Duration of VAC $($ day \pm sd) & $6.73 \pm 0.70$ & $9.67 \pm 1.56$ & 0.445 \\
\hline Duration of union $($ month \pm sd) & $4.13 \pm 0.43$ & $4.66 \pm 0.54$ & 0.328 \\
\hline Intial wound dimensions $\left(\mathrm{cm}^{2}\right)($ range) & $119.11(20-450)$ & $277.43(48-275)$ & 0.021 \\
\hline Shrinkage $(\%)$ (range) & 99.99 & $44.80(20-60)$ & 0.001 \\
\hline
\end{tabular}

Table 2: Comparison of patients by development of infection

\begin{tabular}{|l|l|l|l|}
\hline Parameters & No infection $(\mathbf{n}=\mathbf{2 2})$ & With infection $(\mathbf{n}=8)$ & P \\
\hline Age (year) & $27.81 \pm 3.52$ & $34.21 \pm 10.92$ & 0.228 \\
\hline Time between trauma initial debridement (hour \pm sd) & $8.90 \pm 1.61$ & $6.33 \pm 2.96$ & 0.382 \\
\hline Duration of VAC $($ day \pm sd) & $8.79 \pm 1.19$ & $7.78 \pm 0.42$ & 0.412 \\
\hline Duration of union $($ month \pm sd) & $3.97 \pm 0.29$ & $6.33 \pm 0.88$ & 0.004 \\
\hline Intial wound dimensions $\left(\mathrm{cm}^{2}\right)($ range) & $188.90(20-750)$ & $333.21(80-875)$ & 0.221 \\
\hline
\end{tabular}

\section{DISCUSSION}

The treatment of large open fractures is determined by the degree of soft tissue injury. The major concern of surgeons in large open fractures is the high risk of infection if a wound cannot be closed primarily. ${ }^{15}$ Removal of the tissues is the best way to reduce the risk of infection in open wounds. In such types of open wounds, VAC dressing can be easily applied. ${ }^{16}$ In addition, VAC also prevents contamination by microorganisms of hospital origin to open wounds. Studies have shown that most of the pathogens infecting open wounds are derived from the hospital environment. ${ }^{17}$

The goals of wound healing are to minimize blood loss and to restore a newly formed, intact epithelial barrier as soon as possible. Factors that affect wound healing are the availability of vascular supply and the rate of neovascularization. ${ }^{18}$

Hou et al. showed that the duration of wound healing in VAC was decreased with Type III open tibial fracture. ${ }^{19}$ The mean duration of VAC dressing in patients with and without the development of infection in this present study was $7.78 \pm$ 0.42 days and $8.79 \pm 1.19$ days, respectively. Ulusal et al. showed a significant reduction in the wound dimensions with the use of VAC. ${ }^{20}$

In this study, we have found that VAC decreases the size of wounds that are difficult to close, and it provided negative pressure in wounds that also reduced the chances of infection from the hospital environment. We observed that VAC also decreased wound dimensions. Our study showed that vascularisation and the rate of granulation tissue formation were increased by VAC. This led to faster wound healing and average healthier wound conditions. The mean decrease in the wound dimensions was found to be $43.06 \%$ between pre and post-VAC applications. This suggests that VAC is also helping to reduce wound dimensions. As compared to daily dressing in conventional therapy, the number of dressing changes reduced due to every 48 hours changing of VAC. This led to better patient compliance and reduced the patient's inconvenience.

\section{CONCLUSION}

VAC application increases the patient's comfort by reducing the need for dressing changes, improves blood circulation, accelerates the formation of granulation tissue, reduces the rate of infection from the hospital environment, decreases edema, alleviates the need for secondary interventions, and also decreases wound dimensions.

\section{Acknowledgement: None}

Conflict of Interest: None 


\section{Source of Funding: None}

\section{Ethical Approval: Approved}

\section{REFERENCES}

1. Gustilo RB, Anderson JT. Prevention of infection in the treatment of one thousand and twenty-five open fractures of long bones: retrospective and prospective analyses. J Bone Jt Surg Am. 1976;58:453458.

2. Turen $\mathrm{CH}$, DiStasio AJ. Treatment of grade IIIB and grade IIIC open tibial fractures. Orthop Clin N Am. 1994;25:561-571.

3. Jacob E, Erpelding JM. A retrospective analysis of open fractures sustained by U.S. military personnel during operation just cause. Mil Med. 1992;157: 552-556.

4. Court-Brown CM. Reamed intramedullary tibial nailing. An overview and analysis of 1106 cases. J Orthop Trauma. 2004;18:96101.

5. Harley BJ, Beaupre LA, Jones CA, et al. The effect of time to definitive treatment on the rate of nonunion and infection in open fractures. J Orthop Trauma. 2002;16: 484490.

6. Khatod M, Botte MJ, Hoyt DB, et al. Outcomes in open tibia fractures: relationship between delay in treatment and infection. J Trauma. 2003;55:949-954.

7. Schandelmaier P, Krettek C, Rudolf J, et al. Superior results of tibial rodding versus external fixation in grade 3B fractures. Clin Orthop Relat Res. 1997;342: 164-172.

8. Hoogendoorn JM, van der Werken C. Grade III open tibial fractures. Functional outcome with quality of life in amputees versus patients with successful reconstruction. Injury. 2001;32:329-334.

9. Cross WW 3rd, Swiontkowski MF. Treatment principles in the management of open fractures. Indian J Orthop. 2008;42(4): 377-386. doi:10.4103/0019-5413.43373.

10. Huang C, Leavitt T, Bayer LR, Orgill DP. Effect of negative pressure wound therapy on wound healing. Curr Probl Surg. 2014; 51:301-31.

11. Argenta LC, Morykwas MJ. Vacuumassisted closure: a new method for wound control and treatment: clinical experience. Annals of Plastic Surgery. 1997; 38:563576.

12. Reuler JB, Conney TG. The pressure sore: pathophysiology and principles of management. Ann Intern Med. 1981;94: 661-665.

13. Witkowski JA, Parish LC. Histopathology of the decubitus ulcer. J Am Acad Dermatol. 1982; 6:1014- 1021.

14. Prokuski L. Negative pressure dressings for open fracture wounds. Iowa Orthop J. 2002; 22:20-24.

15. Olesen UK, Juul R, Bonde CT, Moser C, McNally M, Jensen LT et al. A review of forty five open tibial fractures covered with free flaps. Analysis of complications, microbiology and prognostic factors. Int Orthop. 2015; 39:1159-66.

16. Gabriel A, Rauen B. Simplified negative pressure wound therapy with instillation: advances and recommendations. Plast Surg Nurs. 2014; 34:88-92.

17. Weitz-Marshall AD, Bosse MJ. Timing of closure of open fractures. J Am Acad Orthop Surg. 2002; 10:379-84.

18. Hunt TK. Vascular factors govern healing in chronic wounds. In: Barbul A, Caldwell MD, Eaglstein WH, et al., editors. Clinical and Experimental Approach to Dermal and Epidermal Repair: Normal and Chronic Wounds. New York, NY, USA: Wiley \& Leiss; 1991: 1-17.

19. Hou Z, Irgit K, Strohecker KA, Matzko ME, Wingert NC, DeSantis JG, et al. Delayed flap reconstruction with vacuum-assisted closure management of the open IIIB tibial fracture. J Trauma. 2011; 71:1705-8.

20. Ulusal AE, Sahin MS, Ulusal B, Cakmak G, Tuncay C. Negative pressure wound therapy in patients with diabetic foot. Acta Orthop Traumatol Turc. 2011; 45:254-60.

How to cite this article: Suman H, Krishna J, Sharma Y et.al. Role of VAC dressing in the large open fracture: a single center prospective study from Indore. International Journal of Research and Review. 2021; 8(4): 22-25. DOI: https://doi.org/10.52403/ijrr.20210404 